\title{
PAPER
}

1

\section{Benzothiadiazole - an excellent acceptor for indacenodithiophene based polymer solar cells}

Deyu Liu, Liang Sun, Zhengkun Du, Manjun Xiao, Chuantao Gu, Ting Wang, Shuguang Wen, Mingliang Sun* and Renqiang Yang*

Indacenodithiophene is copolymerized with di-2-thienyl$2^{\prime}, 1^{\prime}, 3^{\prime}$-benzothiadiazole or terthiophene. The reason why the benzothiadiazole based polymer shows high PCE is discussed.

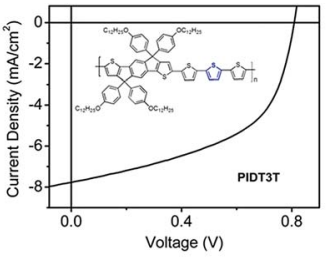

$E_{g}: 2.08 \mathrm{eV}$ HOMO: $-5.35 \mathrm{eV}$ PCE: $3.26 \%$
VS

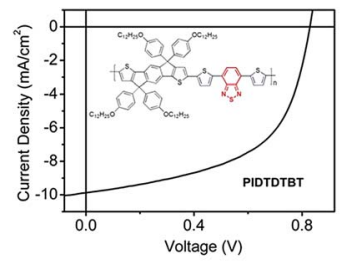

$E_{\mathrm{g}}: 1.75 \mathrm{eV}$ HOMO: $-5.30 \mathrm{eV}$ PCE: $4.52 \%$

Translation errors between word-processor files and typesetting systems can occur so the whole proof needs to be read. Please pay particular attention to: tabulated material; equations; numerical data; figures and graphics; and references. If you have not already indicated the corresponding author(s) please mark their name(s) with an asterisk. Please e-mail a list of corrections or the PDF with electronic notes attached - do not change the text within the PDF file or send a revised manuscript. Corrections at this stage should be minor and not involve extensive changes. All corrections must be sent at the same time.

Please bear in mind that minor layout improvements, e.g. in line breaking, table widths and graphic placement, are routinely applied to the final version.

We will publish articles on the web as soon as possible after receiving your corrections; no late corrections will be made.

Please return your final corrections, where possible within 48 hours of receipt by e-mail to: advances(arsc.org 


\section{Queries for the attention of the authors}

Journal: RSC Advances

5 Paper: c4ra06967f

Title: Benzothiadiazole - an excellent acceptor for indacenodithiophene based polymer solar cells

Editor's queries are marked like this... $\mathbf{1}$, and for your convenience line numbers are inserted like this... 5

Please ensure that all queries are answered when returning your proof corrections so that publication of your article is not delayed.

\begin{tabular}{|l|l|l|}
\hline $\begin{array}{l}\text { Query } \\
\text { Reference }\end{array}$ & Query & Remarks \\
\hline 1 & $\begin{array}{l}\text { For your information: You can cite this article before you receive } \\
\text { notification of the page numbers by using the following format: } \\
\text { (authors), RSC Adv., (year), DOI: 10.1039/c4ra06967f. }\end{array}$ & \\
\hline 2 & $\begin{array}{l}\text { Please carefully check the spelling of all author names. This is } \\
\text { important for the correct indexing and future citation of your } \\
\text { article. No late corrections can be made. }\end{array}$ & \\
\hline 3 & $\begin{array}{l}\text { A citation to Fig. } 6 \text { has been added here, please check that the } \\
\text { placement of this citation is suitable. If the location is not suitable, } \\
\text { please indicate where in the text the citation should be inserted. }\end{array}$ & \\
\hline
\end{tabular}


1

I

Cite this: DOI: 10.1039/c4ra06967f

10

\section{Introduction} 66781927; Tel: +86-532-66781690

\title{
Benzothiadiazole - an excellent acceptor for indacenodithiophene based polymer solar cells
}

\author{
Deyu Liu, ${ }^{\text {ab }}$ Liang Sun, ${ }^{\mathrm{b}}$ Zhengkun Du, ${ }^{\mathrm{b}}$ Manjun Xiao, ${ }^{\mathrm{b}}$ Chuantao Gu, ${ }^{\mathrm{b}}$ Ting Wang, ${ }^{\mathrm{b}}$ \\ Shuguang Wen, ${ }^{b}$ Mingliang Sun ${ }^{\star a}$ and Renqiang Yang ${ }^{\star b}$
}

Two tetradodeoxyphenyl-substituted indacenodithiophene (IDT) based polymers, PIDT3T and PIDTDTBT, were achieved by copolymerizing IDT with terthiophene (3T) or di-2-thienyl-2', $1^{\prime}, 3^{\prime}$-benzothiadiazole (DTBT). Although these two polymers show significantly different UV-vis absorption spectra and band gaps (2.08 eV and $1.75 \mathrm{eV})$, the HOMO levels $(-5.35 \mathrm{eV}$ and $-5.30 \mathrm{eV})$ of these polymers are almost the same. Polymer solar cells (PSCs) based on polymers with the benzothiadiazole (BT) unit show relatively high short-circuit current density $\left(J_{s c}\right)$ due to the relatively wide and high photo-electronic response and high hole mobility. Thanks to the four long aryl side chains on IDT, the polymer thin film shows an amorphous nature, and the AFM root-mean-square roughness (RMS) value of the polymer/PCBM blend film is only around $0.3 \mathrm{~nm}$ which can contribute to the homogenous bulk heterojunction structures without significant phase separation. Finally, decent power conversion efficiency (PCE) of $4.52 \%$ is achieved by the benzothiadiazole based polymer and $\mathrm{PC}_{71} \mathrm{BM}$ composite. By comparison study, we demonstrate why BT is an excellent acceptor unit for indacenodithiophene-based PSCs.

Polymer solar cells (PSCs) have attracted increasing interest due to their potential for fabrication of light-weight, large-area, and flexible light-harvesting devices through low-cost solution processing. ${ }^{1-7}$ With prolonged effort, the PCE of PSCs has already exceeded $10 \% .{ }^{8}$ PSCs usually adopt a bulk-heterojunction (BHJ) structure, where a photoactive layer consists of an interpenetrating network of $\pi$-conjugated polymer donors and soluble fullerene or nanocrystal acceptors. ${ }^{9}$ Because donor polymer can harvest most of the solar energy, more efforts have been focused on developing conjugated polymers with small band gap and proper energy levels that can be used as a donor material to complement fullerene-based acceptors. ${ }^{10-14}$

Among different donor materials, indaxenodithiophene (IDT) based conjugated polymers have attracted much attention in optoelectronic devices. ${ }^{15-17}$ In IDT, the rigid ring unit could enhance both the degree of conjugation ${ }^{18}$ and the co-planarity of the molecular backbones. A series of polymers based on IDT, BT and thiophene have been synthesized (Scheme 1). ${ }^{16,19-24}$ The highest PCE reached $7 \%$ based the corresponding PSCs. ${ }^{25} \mathrm{Jen}$ $R^{t}$ all. studied several high performance D-A polymers based on

${ }^{a}$ Institute of Material Science and Engineering, Ocean University of China, Qingdao 266100, People's Republic of China. E-mail: mlsun@ouc.edu.cn; Fax: +86-532-

${ }^{b}$ CAS Key Laboratory of Bio-based Materials, Qingdao Institute of Bioenergy and Bioprocess Technology, Chinese Academy of Sciences, Qingdao 266100, People's Republic of China. E-mail: yangrq@qibebt.ac.cn; Fax: +86-532-80662778; Tel: +86532-80662700
IDT and different acceptor units. ${ }^{26-29}$ The IDT-based polymers have presented pretty high mobility and the appropriate optical properties, which can facilitate the charge transport simultaneously enhance the absorption of sunlight and subsequently lead to high $J_{\mathrm{sc}}$ of PSCs devices. ${ }^{30}$ Therefore, both thiophene and BT are promising building blocks for IDT-based polymers. Among these materials, IDT and di-2-thienyl-2', $1^{\prime}, 3^{\prime}$-benzothiadiazole (DTBT) based high performance polymer solar cells showed PCE up to $6 \% .{ }^{24}$ In general, the strategy to improve the PCE of solar cells devices is to adjust band gap of polymers. ${ }^{31,32}$ Low band gap could enhance the absorption at long wavelengths. However, usually lowering the band gap will lead to the change of the HOMO level, which could reduce $V_{\mathrm{oc}}$ of the devices. Increasing $J_{\mathrm{sc}}$ and keeping high $V_{\mathrm{oc}}$ is a contradiction, but IDT and di-2-thienyl-2' $1^{\prime}, 3^{\prime}$-benzothiadiazole (DTBT) based polymer

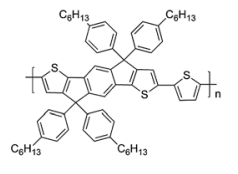

PIDTT

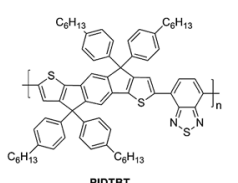

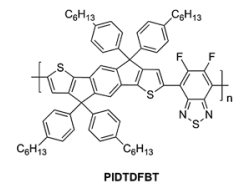

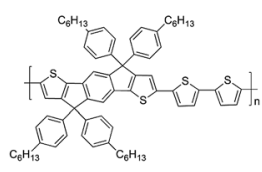

PIDTDT

PIDTDFBT

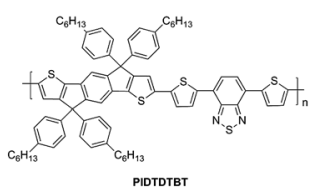

PIDTDTBT

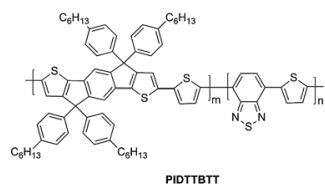

Scheme 1 Molecular structures of IDT-based polymers. 
solar cells can show high $J_{\mathrm{sc}}$ resulting from wide absorption and acceptable $V_{\text {oc }}$ resulting from deep HOMO energy level. ${ }^{24}$

Typically, the side chain of IDT based polymer was hexyl, and molecular weights $\left(M_{\mathrm{n}}\right)$ of polymers (Scheme 1) were exhibited to be in the range of $15-25 \mathrm{~K}^{16,19-24}$ Longer side chains on the donor can produce better solubility of the polymer and intermediate oligomers, which may potentially lead to higher molecular weight. ${ }^{33}$ On the other hand, long side chains could reduce the tendency for crystallization to help to obtain the complete noncrystalline materials, which could avoid considering that crystallinity impacts on spectral red shift and mobility in polymer solar cells study. Especially in chemical structure comparison study, long sided chained polymer is favorite.

Here, we synthesized a new tetra-dodeoxyphenyl long chain substituented indacenodithiophene (IDT) derivative and used it as a building unit for polymers. Two IDT-based copolymers PITD3T and PIDTDTBT (Scheme 2) with different building blocks were prepared by Stille polycondensation, and their thermal, optical, electrochemical and photovoltaic properties were investigated. Thanks to the long dodecyl chain, PIDT3T and PIDTDTBT showed high molecular weights (Table 1). Especially, PIDT3T showed one of the highest molecular weights of $61.7 \mathrm{~K}$ in IDT based polymers. Compared with PIDT3T polymer, the benzothiadiazole unit in PIDTDTBT polymer was introduced to lower the band gap and increase the absorption. Fortunately, the introduction of BT could lower the band gap and increase $J_{\text {sc }}$ effectively, while the HOMO level did not changed. Thanks to the amorphous nature of these polymers, the comparison of two polymers is completely due to difference of the thiophene and the BT in the middle of other units. In this paper, by comparison study we demonstrate why BT is an excellent acceptor unit for indacenodithiophene-based PSCs.

\section{Results and discussion}

\subsection{Synthesis of monomers and polymers}

The synthetic routes of the monomer (IDT) and the copolymer are depicted in Scheme 3. The synthesis of the indaxenodithiophene (IDT) was generally based on the previous literature. ${ }^{34}$ The TMS groups on compound $\mathbf{1}$ (Scheme 3) were introduced to facilitate the later intramolecular cyclization reactions. Two polymers, PIDT3T and PIDTDTBT, were synthesized by using palladium-catalyzed Stille coupling copolymerization of IDT with $3 \mathrm{~T}$ and DTBT. ${ }^{35}$ The structures of two polymers were confirmed by ${ }^{1} \mathrm{H}$ NMR spectroscopy. Both polymers showed good solubility in common organic solvents, such as chloroform, toluene and chlorobenzene, due to the four dodeoxyphenyl side chains in the IDT repeat unit. The

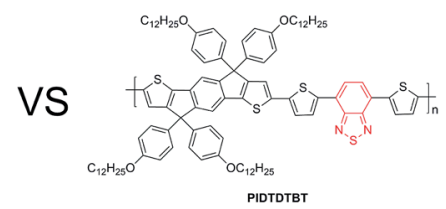

Scheme 2 Molecular structures of PIDT3T and PIDTDTBT.
Table 1 Molecular weights and thermal properties of PIDT3T and DIDDTBT

\begin{tabular}{lllll}
\hline Polymers & $M_{\mathrm{n}}$ & $M_{\mathrm{w}}$ & PDI & $T_{\mathrm{d}}\left({ }^{\circ} \mathrm{C}\right)$ \\
\hline PIDT3T & $61.7 \mathrm{~K}$ & $62.6 \mathrm{~K}$ & 1.01 & 374 \\
PIDTDTBT & $35.1 \mathrm{~K}$ & $44.3 \mathrm{~K}$ & 1.26 & 422 \\
\hline
\end{tabular}

number-average molecular weight $\left(M_{\mathrm{n}}\right)$ and polydispersity index (PDI) were measured by gel permeation chromatography (GPC) using THF as the eluant and polystyrenes as the internal standards, and the results were listed in Table 1 . The $M_{\mathrm{n}}$ of PIDT3T and PIDTDTBT are $61.7 \mathrm{~K}$ and $35.1 \mathrm{~K}$, respectively. Molecular weights of the copolymers are relatively high, probably due to the good solubility of IDT monomer with long side chains.

\subsection{Thermal analysis}

The thermal properties of the polymers were determined by differential scanning calorimetry (DSC) and thermogravimetric analysis (TGA), as shown Fig. 1. DSC thermogram didn't show apparent thermal transitions for PIDT3T and PIDTDTBT polymer, implying their amorphous nature. The TGA analysis reveals that the onset temperature with $5 \%$ weight-loss $\left(T_{\mathrm{d}}\right)$ of PIDT3T and PIDTDTBT are $374{ }^{\circ} \mathrm{C}$ and $422{ }^{\circ} \mathrm{C}$, respectively. DTBT unit has higher thermal stability than $3 \mathrm{~T}$ unit, ${ }^{36,37}$ which results in higher thermal stability of PIDTDTBT polymer. This indicates that the thermal stability of the polymers is good enough for PSCs applications.

\subsection{Optical properties}

The UV-vis absorption spectra of PIDT3T and PIDTDTBT in chloroform solution and in thin film are shown in Fig. 2, respectively, and the corresponding absorption properties are
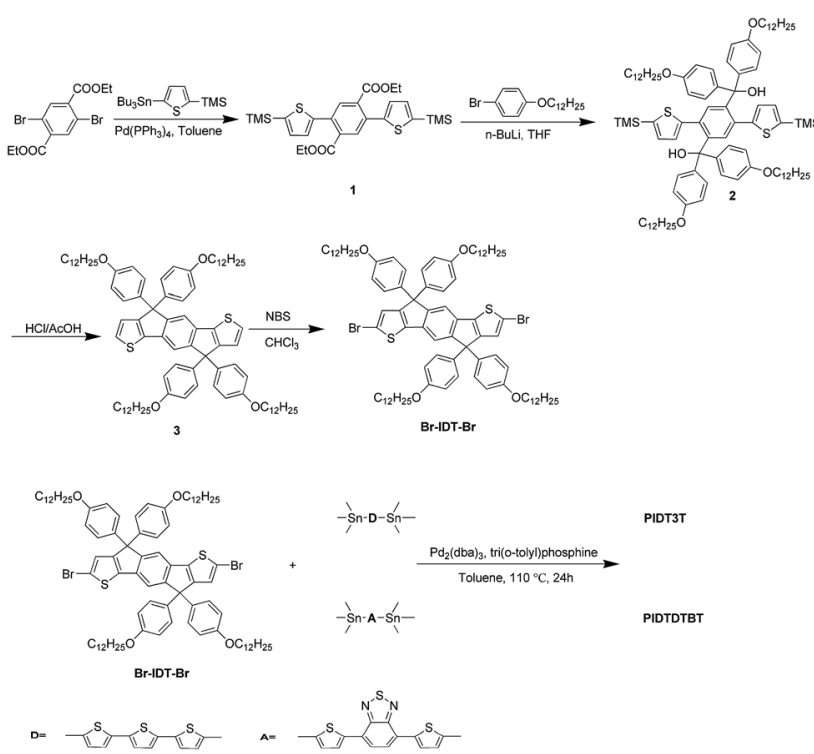

Scheme 3 Synthetic routes of the IDT monomer and the IDT-based copolymers. 


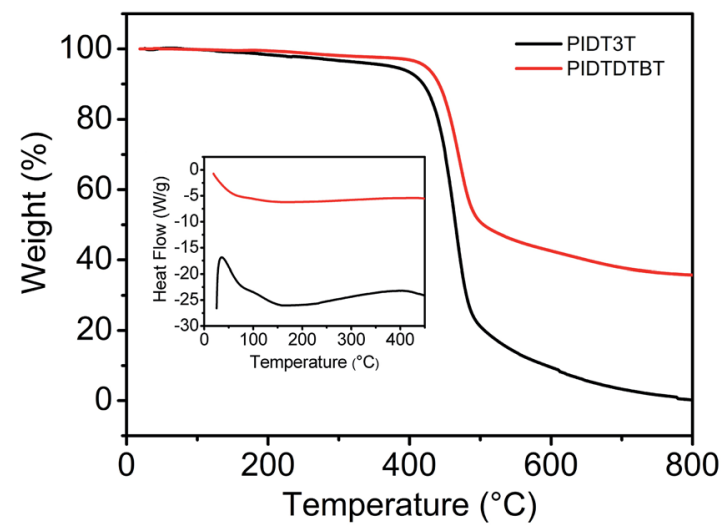

Fig. 1 TGA of the polymers with a heating rate of $10^{\circ} \mathrm{C} \mathrm{min}^{-1}$ under an inert atmosphere (inset: DSC thermogram of the polymers).

summarized in Table 2. PIDT3T exhibited one absorption band due to the $\pi-\pi^{*}$ transition with the absorption maximum at 516 nm. PIDTDTBT exhibited two absorption bands due to the $\pi-\pi^{*}$ transition and the intramolecular charge transfer with the absorption maximum at $450 \mathrm{~nm}$ and $606 \mathrm{~nm}$ in chloroform solution. In the thin film, both polymers exhibit a red-shift in the absorption maximum and onset, which is attributed to solid state packing effects. Compared the absorption in thin film with that in solution, PIDTDTBT polymer exhibits a greater red-shift compared to PIDT3T, which is attributed to more effective $\pi-\pi$ stacking: ${ }^{38,39}$ PIDTDTBT polymer shows more planar polymer structure and packs better than PIDT3T. The optical band gaps $\left(E_{\mathrm{g}}^{\mathrm{opt}}\right)$ of PIDT3T and PIDTDTBT were estimated to be $2.08 \mathrm{eV}$ and $1.75 \mathrm{eV}$ according to $E_{\mathrm{g}}^{\mathrm{opt}}=1240 / \lambda$. Due to the introduction of BT unit, the band gap of PIDTDTBT was obviously lowered compared with PIDT3T. The lower band gap of PIDTDTBT should be beneficial to its application as donor material in PSCs.

\subsection{Electrochemical properties}

The electrochemical cyclic voltammetry (CV) was performed for determining the highest occupied molecular orbital (HOMO) and the lowest unoccupied molecular orbital (LUMO) energy

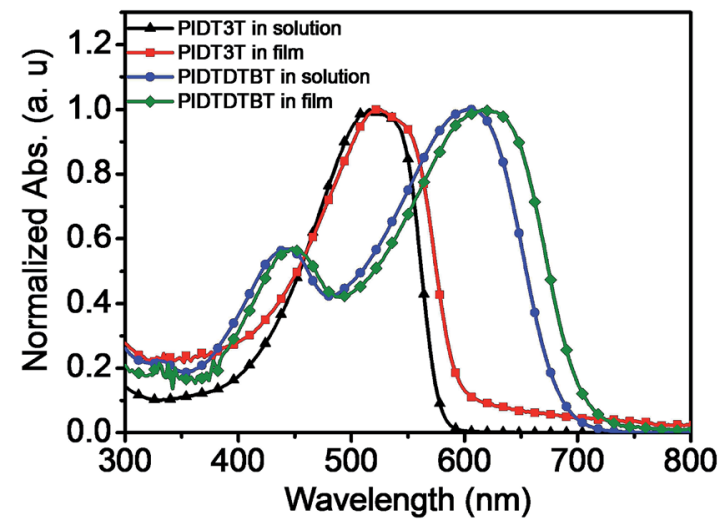

Fig. 2 Normalized absorption spectra of the PIDT3T and PIDTDTBT in chloroform solution and in thin film. levels of the conjugated polymers. ${ }^{40}$ Fig. 3 shows the cyclic voltammogram (CV) properties of the polymers. A three electrode cell consisting of a glassy carbon working electrode, a platinum wire counter electrode and a saturated calomel reference electrode has been used. The potentials were internally calibrated using the $\mathrm{Fc} / \mathrm{Fc}^{+}$redox couple. The redox potential of the $\mathrm{Fc} / \mathrm{Fc}^{+}$internal reference is found to be $0.43 \mathrm{~V} v s$. SCE. According to the empirical equation,

$$
\begin{aligned}
& \mathrm{HOMO}=-\left(E_{\mathrm{ox}}+4.4\right)(\mathrm{eV}) \\
& \mathrm{LUMO}=-\left(E_{\mathrm{re}}+4.4\right)(\mathrm{eV})
\end{aligned}
$$

The results of the electrochemical properties are listed in Table 2. Compared with PIDT3T, the LUMO energy levels of PIDTDTBT decreased significantly due to the electron-withdrawing ability of the acceptor unit, but the HOMO energy levels of the polymer changed little, which is possibly due to similar oxidation potential of 3T and DTBT. These two polymers show deep HOMO energy levels $(\sim-5.3 \mathrm{eV})$, which is desirable for good stability in the air and high open circuit voltage $\left(V_{\mathrm{oc}}\right)$ in PSCs.

\subsection{Photovoltaic properties}

To investigate and compare the photovoltaic properties of the polymers, bulk heterojunction PSCs devices with a configuration of ITO/PEDOT:PSS/polymer:PC ${ }_{61} \mathrm{BM} / \mathrm{Ca} / \mathrm{Al}$ were fabricated by the method of solution processing as our previous work. ${ }^{41-43}$ And then, we further optimized the device performances using $\mathrm{PC}_{71} \mathrm{BM}$ acceptor with device configuration ITO/PEDOT:PSS/ polymers: $\mathrm{PC}_{71} \mathrm{BM}(1: 3) / \mathrm{Ca} / \mathrm{Al}$. Fig. 4 exhibits the $J-V$ curves of the PSCs under illumination of AM $1.5 \mathrm{G}, 100 \mathrm{~mW} \mathrm{~cm}^{-2}$. Table 3 summarized the detailed device performances. Finally, the best solar cell obtained from PIDT3T:PC ${ }_{71} \mathrm{BM}(1: 3)$ showed a PCE of $3.26 \%$ with an $V_{\mathrm{oc}}$ of $0.81 \mathrm{~V}$, a $J_{\mathrm{sc}}$ of $7.75 \mathrm{~mA} \mathrm{~cm} \mathrm{~cm}^{-2}$, and a FF of $51.93 \%$ and PIDTDTBT showed a PCE of $4.52 \%$ with an $V_{\text {oc }}$ of 0.83 $\mathrm{V}, \mathrm{a} J_{\mathrm{sc}}$ of $9.85 \mathrm{~mA} \mathrm{~cm}^{-2}$, and a FF of $53.26 \%$ at the same condition. The $V_{\text {oc }}$ of two polymers based PSCs devices was almost the same due to the similar HOMO level. Compared to the PIDT3T, PIDTDTBT showed higher $J_{\mathrm{sc}}$ value, which may be originated from the relatively lower band gap and stronger $\pi-\pi$ stacking interaction. The external quantum efficiency (EQE) curves of the devices based on PIDT3T:PC ${ }_{71} \mathrm{BM}$ and PIDTDTBT:PC ${ }_{71} \mathrm{BM}(1: 3)$ are shown in Fig. 5. The EQE value of PIDTDTBT is higher than that of PIDT3T in most parts of spectra (320-700 nm) and the maximum value reaches $61 \%$. It indicates that PIDTDTBT has good photo response among the absorption range. The calculated current density from the EQE measurement were 7.66 and $9.74 \mathrm{~mA} \mathrm{~cm}^{-2}$, respectively for PIDT3T and PIDTDTBT, which agree well with the $J_{\text {sc }}\left(7.75 \mathrm{~mA} \mathrm{~cm}^{-2}\right.$ for PIDT3T and $9.85 \mathrm{~mA} \mathrm{~cm}^{-2}$ for PIDTDTBT) obtained from the $J-V$ measurements (Fig. 6).

Mobility measurements via space charge limited current (SCLC) method ${ }^{40}$ disclose a hole mobility of $2.35 \times 10^{-4} \mathrm{~cm}^{2}$ $\mathrm{V}^{-1} \mathrm{~s}^{-1}$ for the PIDTDTBT:PC ${ }_{71} \mathrm{BM}$ device, higher than that of the PIDT3T:PC ${ }_{71} \mathrm{BM}$ device $\left(1.31 \times 10^{-4} \mathrm{~cm}^{2} \mathrm{~V}^{-1} \mathrm{~s}^{-1}\right)$. This could be a potential reason that PIDTDTBT:PC ${ }_{71} \mathrm{BM}$ device exhibits larger $J_{\mathrm{sc}}$ and $\mathrm{FF}$ than PIDT3T:PC ${ }_{71} \mathrm{BM}$ device. 
Table 2 Optical and electrochemical properties of the polymers

\begin{tabular}{|c|c|c|c|c|c|c|}
\hline Polymer & $\lambda_{\max }$ solution $(\mathrm{nm})$ & $\lambda_{\max }$ film $(\mathrm{nm})$ & $E_{\mathrm{g}}^{\mathrm{opt}}$ film $(\mathrm{eV})$ & $E_{\mathrm{g}}^{\mathrm{cv}}(\mathrm{eV})$ & HOMO $(\mathrm{eV})$ & LUMO (eV) \\
\hline PIDT3T & 516 & 522 & 2.08 & 1.8 & -5.35 & -3.55 \\
\hline PIDTDTBT & 606 & 622 & 1.75 & 1.6 & -5.30 & -3.70 \\
\hline
\end{tabular}

10

15

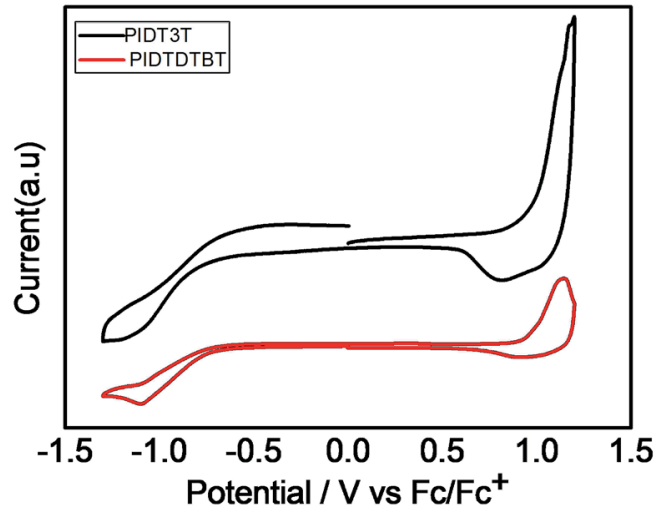

Fig. 3 Cyclic voltammogram of PIDT3T and PIDTDTBT.

25

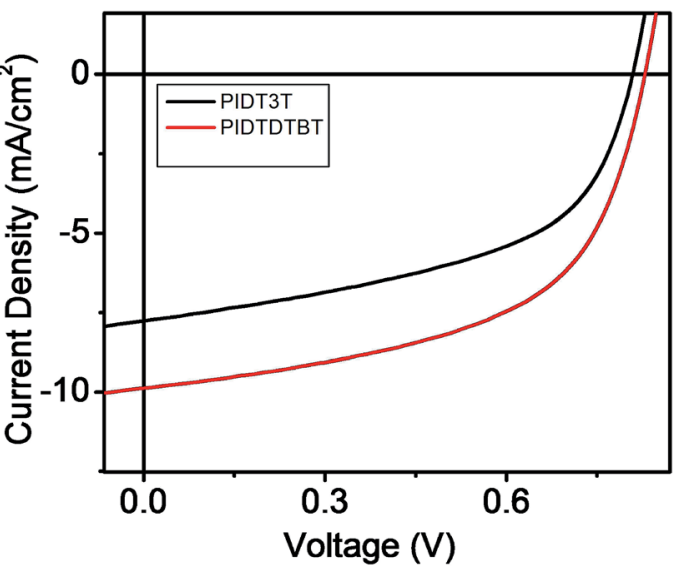

Fig. $4 J-V$ curves of the PSCs based on the blend of PIDT3T or PIDTDTBT/PC $C_{71} B M$ under the illumination of $A M 1.5 \mathrm{G}, 100 \mathrm{~mW} \mathrm{~cm}^{-2}$.

Table 3 Solar cells devices performance of PIDT3T and PIDTDTBT ${ }^{a}$

\begin{tabular}{|c|c|c|c|c|}
\hline Polymers/acceptor & $V_{\mathrm{oc}} / \mathrm{V}$ & $J_{\mathrm{sc}} / \mathrm{mA} \mathrm{cm}^{-2}$ & $\mathrm{FF} /(\%)$ & $\mathrm{PCE} /(\%$ \\
\hline $\mathrm{PIDT} 3 \mathrm{~T} / \mathrm{PC}_{61} \mathrm{BM}$ & 0.81 & 5.06 & 49.7 & 2.03 \\
\hline PIDT3T/PC ${ }_{71} \mathrm{BM}$ & 0.81 & 7.75 & 51.93 & 3.26 \\
\hline PIDTDTBT/PC ${ }_{61} \mathrm{BM}$ & 0.85 & 7.13 & 58.48 & 3.56 \\
\hline PIDTDTBT/PC ${ }_{71} \mathrm{BM}$ & 0.83 & 9.85 & 55.26 & 4.52 \\
\hline
\end{tabular}

${ }^{a}$ The active layers were annealed at $150{ }^{\circ} \mathrm{C}$ for $10 \mathrm{~min}$.

\subsection{Morphological characterization}

Atomic force microscopy (AFM) was used to investigate the morphology of the two polymers: $\mathrm{PC}_{71} \mathrm{BM}$ blend films annealed at $150{ }^{\circ} \mathrm{C}$. The height images and phase images of the blends are

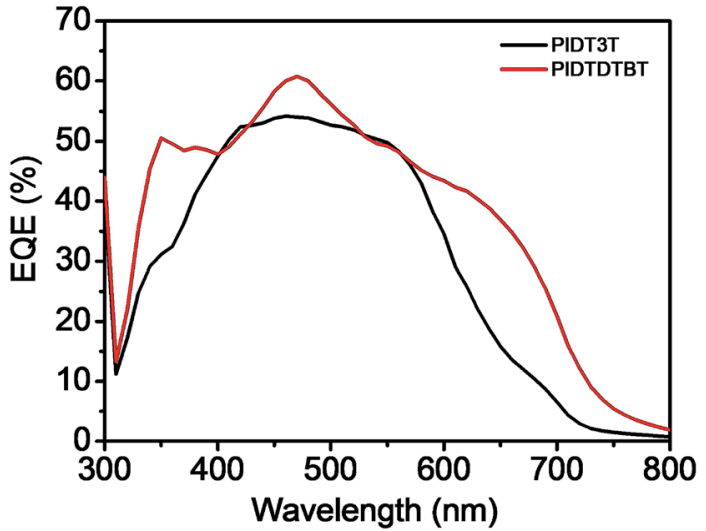

Fig. 5 들 of curves of the PSCs based on the blend of PIDT3T or PIDTDTBT/PC ${ }_{71} \mathrm{BM}$
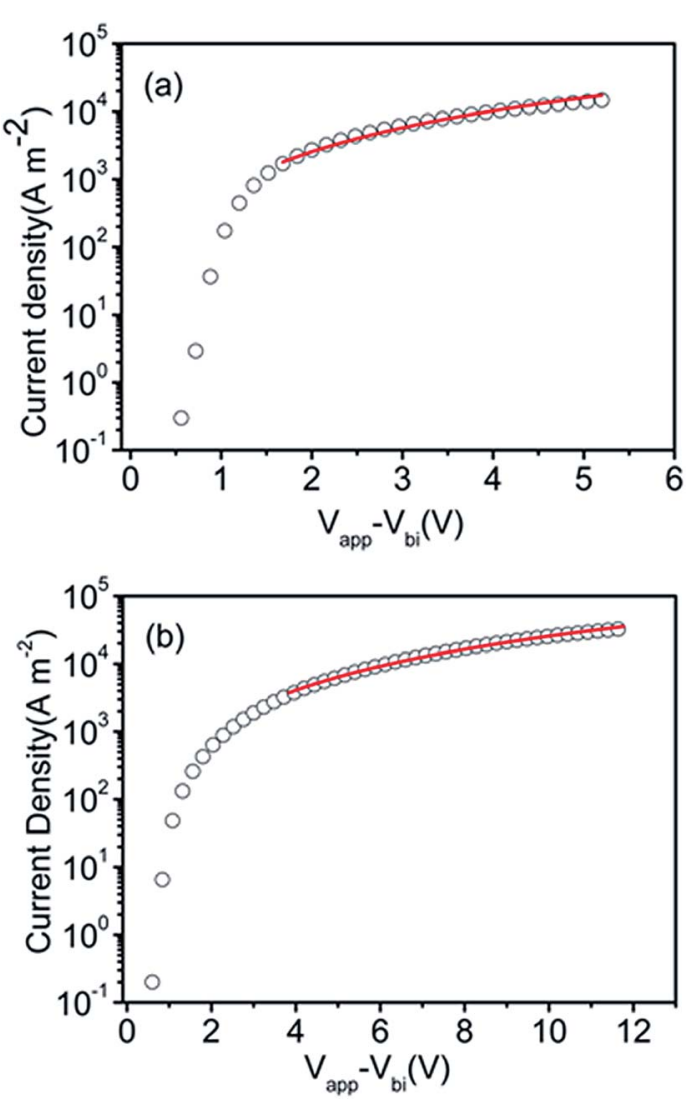

Fig. 6 Current density (J)-voltage ( $V$ curves for PIDT3T based device (a) and PIDTDTBT based device (b) (the symbols are experimental data for transport of hole, and the red line is fitted according to the spacecharge-limited-current model). 

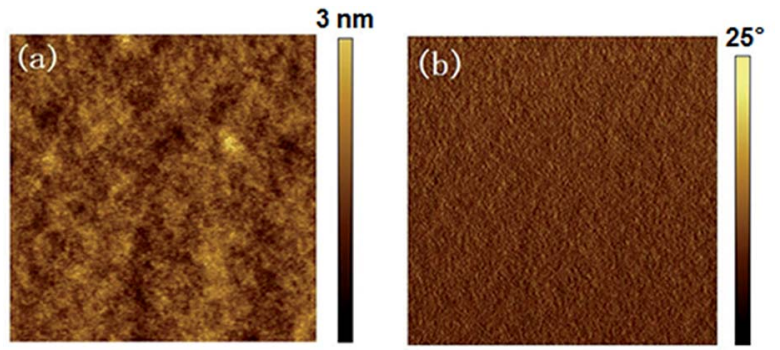

10
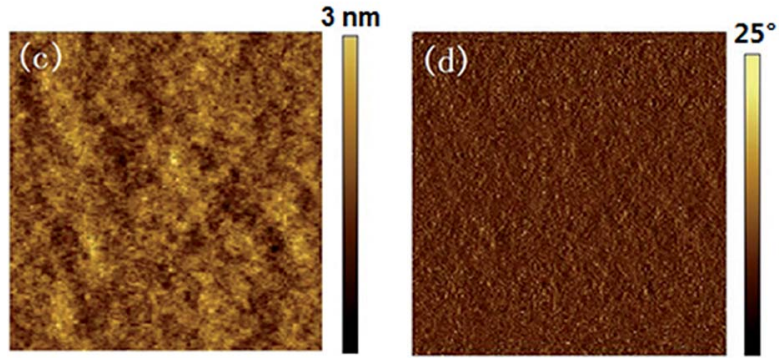

Fig. 7 AFM height (a) and phase (b) images of the PIDT3T:PC ${ }_{71} B M$ (1:3) blend films annealed at $150{ }^{\circ} \mathrm{C}$; AFM height (c) and phase (d) images of the PIDTDTBT:PC ${ }_{71} \mathrm{BM}(1: 3)$ blend films annealed at $150{ }^{\circ} \mathrm{C}$ (all the images are $4 \mu \mathrm{m} \times 4 \mu \mathrm{m}$ ).

Fig. 8 X-ray diffraction (XRD) pattern of the PIDT3T and the PIDTDTBT.

shown in Fig. 7. The blend films of PIDT3T and PIDTDTBT with $\mathrm{PC}_{71} \mathrm{BM}$ showed surface roughness with root-mean-square (RMS) of $0.343 \mathrm{~nm}$ and $0.328 \mathrm{~nm}$, respectively. Although with a smooth surface morphology of the active layer, the device based on PIDT3T has a lower $J_{\mathrm{sc}}$ value than PIDTDTBT which can be attributed to its lower EQE value. The crystallinity of the polymer films was investigated using XRD pattern, as shown in Fig. 8. There are no peaks observed for these polymers in XRD test, indicating their amorphous nature.

\section{Conclusions}

We have successfully synthesized two indacenodithiophenebased polymers PIDT3T and PIDTDTBT. Thanks to the long side chain, the polymers show high (up to $6.0 \mathrm{~K}$ ) molecule weight with narrow PDI and amorphous nature (no crystallization). Although these two polymers show significantly different UV-vis absorption spectrum and band gap (2.08 eV and $1.75 \mathrm{eV})$, the HOMO levels $(-5.35 \mathrm{eV}$ and $-5.30 \mathrm{eV})$ are almost the same. PSCs based on these two materials show almost the same $V_{\text {oc }}$ (around $0.8 \mathrm{~V}$ ) due to the same HOMO level. PSCs based on PIDTDTBT with benzothiadiazole unit show relatively high $J_{\mathrm{sc}}$ and FF due to the relatively wide and high photo-electronic response and high hole mobility. Our comparison study shows that BT is a good acceptor unit in IDT polymer backbone which does broad absorption to increase $J_{\mathrm{sc}}$ of PSCs devices without lowing $V_{\text {oc }}$ of the device due to proper HOMO levels.

\section{Experimental}

\subsection{Materials}

All chemicals, unless otherwise specified, were commercial grade and used as received. Toluene and THF were freshly distilled from sodium and benzophenone ketyl under nitrogen prior to use. 5-(Trimethylsilyl)-2-(tri- $n$-butylstannyl)thiophene, 4-dodeoxy-1-bromobenene, 2,5"-bis(trimethylstannyl)-5, $2^{\prime}, 5^{\prime}, 2^{\prime \prime}$ terthiophene were synthesized as reported in the literature. ${ }^{4-47}$

\subsection{Instruments and measurements}

Nuclear magnetic resonance (NMR) spectra were taken on a Bruker AVANCE-III 600 Spectrometer. High resolution mass spectra (MS) were recorded under APCI mode on a Bruker Maxis UHRTOF spectrometer. All GPC analyses were made using tetrahydrofuran (THF) as eluant and polystyrene standard as reference. Differential scanning calorimetry (DSC) and thermal gravimetric analysis (TGA) measurements were performed on STA-409 at a heating rate of $10{ }^{\circ} \mathrm{C} \mathrm{min}^{-1}$. UV-vis absorption spectrum was measured with a Hitachi U-4100 spectrophotometer. The organic molecule films on quartz used for absorption spectral measurement were prepared by spincoating their chloroform solutions. Cyclic voltammetry (CV) was performed using a CHI660D electrochemical workstation with a glassy carbon working electrode, a saturated calomel reference electrode (SCE) and a platinum wire counter electrode at a scan rate of $100 \mathrm{mV} \mathrm{s}^{-1}$. Tetrabutylammonium phosphorus hexafluoride $\left(\mathrm{Bu}_{4} \mathrm{NPF}_{6}, 0.1 \mathrm{M}\right)$ in acetonitrile was used as the supporting electrolyte. Surface roughness and morphology of thin films were characterized by atomic force microscopy (AFM) on an Agilent 5400 working at the tapping mode. X-ray diffraction (XRD) pattern were recorded on a Bruker D8 Advance.

\subsection{Fabrication and characterization of organic solar cells}

Photovoltaic devices were fabricated on pre-patterned indium tin oxide (ITO) coated glass substrates with a layered structure of ITO/PEDOT:PSS/donor:acceptor/Ca(10 nm)/Al(100 nm). The ITO coated glass substrates were cleaned in ultrasonic bath in acetone, toluene, methanol and isopropyl alcohol sequentially. And then, oxygen plasma treatment was made for $20 \mathrm{~min}$, spincoated with PEDOT:PSS at $5000 \mathrm{rpm}$, and dried under argon for $20 \mathrm{~min}$ at $120^{\circ} \mathrm{C}$. The photosensitive layer was prepared by spincoating a blend solution of the polymers and $\mathrm{PC}_{61} \mathrm{BM}\left(\mathrm{PC}_{71} \mathrm{BM}\right)$ 
with a weight ratio of $1: 3$ in deoxygenated anhydrous $o$ dichlorobenzene at $2000 \mathrm{rpm}$ on the ITO/PEDOT:PSS substrate and then annealed at $150{ }^{\circ} \mathrm{C}$ for $10 \mathrm{~min}$ in a glove box. The thickness of active layer films measured by a Dektak 150 profilometer is around $100 \mathrm{~nm}$. Finally, $\mathrm{Ca}(10 \mathrm{~nm})$ and aluminum $(100 \mathrm{~nm})$ were thermally evaporated at a vacuum of $\sim 2 \times 10^{-4}$ $\mathrm{Pa}$ on top of active layer. The photovoltaic performance was measured under illumination at $100 \mathrm{~mW} \mathrm{~cm}^{-2} \mathrm{AM} 1.5 \mathrm{G}$ irradiation using a Xe arc lamp in an argon atmosphere $\left(<0.1 \mathrm{ppm} \mathrm{H}_{2} \mathrm{O}\right.$ and $\left.\mathrm{O}_{2}\right)$, and the current density-voltage $(J-V)$ curves was obtained by Keithley 2400 . The external quantum efficiency (EQE) was obtained by a source meter, silicon photodiode and a computer-controlled light sourcemonochromator-lock-in system.

\subsection{Synthesis}

4.4.1. Diethyl-1,4-bis(5-trimethylsilylthiophen-2-yl)-2,5benzene-dicarbonate (1). Diethyl-2,5-dibromoterephthalate (3.04 g, 8 mmol), 5-(trimethylsilyl)-2-(tri- $n$-butylstannyl)thiophene $(8.91 \mathrm{~g}, 20 \mathrm{mmol})$ and $\mathrm{Pd}\left(\mathrm{PPh}_{3}\right)_{4}(462 \mathrm{mg}$, $0.4 \mathrm{mmol})$ were mixed in toluene $(60 \mathrm{ml})$ under nitrogen atmosphere. The mixture was heated to reflux for $48 \mathrm{~h}$. After cooled to room temperature, it was poured into water and extracted with ethyl acetate. The combined extracts were dried over $\mathrm{Na}_{2} \mathrm{SO}_{4}$ and filtered, and the solvent was removed under reduced pressure. The residue was purified by column chromatography over silica gel, eluting with petroleum ether and ethyl acetate $(\mathrm{v} / \mathrm{v}, 10 / 1)$ to give (1) as a white solid $(1.29 \mathrm{~g}, 31 \%)$. ${ }^{1} \mathrm{H}$ NMR $\left(600 \mathrm{MHz}, \mathrm{CDCl}_{3}\right): \delta(\mathrm{ppm}) 7.81(\mathrm{~s}, 2 \mathrm{H}), 7.18(\mathrm{~d}, J=3.4$ $\mathrm{Hz}, 2 \mathrm{H}), 7.14(\mathrm{~d}, J=3.4 \mathrm{~Hz}, 2 \mathrm{H}), 4.21(\mathrm{q}, J=7.1 \mathrm{~Hz}, 4 \mathrm{H}), 1.13$ (t, $J=7.1 \mathrm{~Hz}, 6 \mathrm{H}), 0.34(\mathrm{~s}, 18 \mathrm{H})$.

4.4.2. 4,9-Dihydro-4,4,9,9-( $p$-dodeoxyphenyl)-s-indaceno [1,2-b:5,6-b]dithiophene (3). To a solution of 4-dodeoxy-1bromobenene $(6.14 \mathrm{~g}, 18 \mathrm{mmol})$ in THF $(10 \mathrm{ml})$ at $-78{ }^{\circ} \mathrm{C}$, $n$-BuLi (11.25 ml, $18 \mathrm{mmol}, 1.6 \mathrm{M}$ in hexane) was added, and the mixture was keep at $-78{ }^{\circ} \mathrm{C}$ for $1 \mathrm{~h}$, then a solution of compound (1) (1.06 g, $2 \mathrm{mmol})$ in THF (5 ml) was added slowly. The mixture was stirred at room temperature overnight and then poured into water and extracted with chloroform. The combined organic extracts were dried over $\mathrm{Na}_{2} \mathrm{SO}_{4}$ and filtered, and the solvent was removed under reduced pressure. The resulting solid was washed with hexanes to give (2) as a white solid crude product. The white product was then directly dissolved in acetic acid $(25 \mathrm{ml})$ and $1 \mathrm{ml}$ of concentrated hydrochloric was added to the solution. The mixture was stirred at $80{ }^{\circ} \mathrm{C}$ for $2 \mathrm{~h}$. After pouring into water, the mixture was extracted with chloroform. The combined organic extracts were dried over $\mathrm{Na}_{2} \mathrm{SO}_{4}$ and filtered, and the solvent was removed under reduced pressure. The resulting solid was washed with water, an aqueous sodium carbonate solution, and methanol to give (3) as a yellow solid $(1.28 \mathrm{~g}, 51 \%) .{ }^{1} \mathrm{H}$ NMR $(600 \mathrm{MHz}$, $\left.\mathrm{CDCl}_{3}\right): \delta(\mathrm{ppm}) 7.38(\mathrm{~s}, 2 \mathrm{H}), 7.23(\mathrm{~d}, J=4.9 \mathrm{~Hz}, 2 \mathrm{H}), 7.14(\mathrm{dd}, J$ $=6.9 \mathrm{~Hz}, 8 \mathrm{H}), 6.96(\mathrm{~d}, J=4.9 \mathrm{~Hz}, 2 \mathrm{H}), 6.76(\mathrm{~d}, J=8.4 \mathrm{~Hz}, 8 \mathrm{H})$, $3.89(\mathrm{t}, J=6.5 \mathrm{~Hz}, 8 \mathrm{H}), 1.73(\mathrm{~m}, 8 \mathrm{H}), 1.41(\mathrm{~m}, 8 \mathrm{H}), 1.35-1.20(\mathrm{~m}$, $64 \mathrm{H}), 0.87(\mathrm{t}, J=7.0 \mathrm{~Hz}, 12 \mathrm{H})$.
4.4.3. 2,7-Dibromo-4,9-dihydro-4,4,9,9-(p-dodeoxyphenyl)$s$-indaceno[1,2-b:5,6-b'] dithiophene (Br-IDT-Br). To a solution of $3(1.27 \mathrm{~g}, 1 \mathrm{mmol})$ dissolved in chloroform ( $25 \mathrm{ml})$, NBS was added (391 mg, $2.2 \mathrm{mmol}$ ). The mixture was stirred under dark at room temperature overnight and extracted with chloroform and water. The combined organic extracts were dried over $\mathrm{Na}_{2} \mathrm{SO}_{4}$ and filtered, and the solvent was removed under reduced pressure. The residue was purified by column chromatography over silica, eluting with petroleum ether to give the monomer as a yellow solid $(1.35 \mathrm{~g}, 92 \%) .{ }^{1} \mathrm{H}$ NMR $(600 \mathrm{MHz}$, $\left.\mathrm{CDCl}_{3}\right): \delta(\mathrm{ppm}) 7.28(\mathrm{~s}, 2 \mathrm{H}), 7.10(\mathrm{~d}, J=8.8 \mathrm{~Hz}, 8 \mathrm{H}), 6.96(\mathrm{~s}, 2 \mathrm{H})$, $6.77(\mathrm{~d}, J=8.9 \mathrm{~Hz}, 8 \mathrm{H}), 3.90(\mathrm{t}, J=6.5 \mathrm{~Hz}, 8 \mathrm{H}), 1.74(\mathrm{~m}, 8 \mathrm{H}), 1.42$ $(\mathrm{m}, 8 \mathrm{H}), 1.35-1.20(\mathrm{~m}, 64 \mathrm{H}), 0.88(\mathrm{t}, J=7.0 \mathrm{~Hz}, 12 \mathrm{H}) .{ }^{13} \mathrm{C}$ NMR $\left(151 \mathrm{MHz}, \mathrm{CDCl}_{3}\right): \delta(\mathrm{ppm}) 158.20,155.13,152.86,141.14$, 135.89, 134.90, 128.91, 125.92, 117.05, 114.30, 113.81, 67.96, $62.71,31.92,29.66,29.63,29.60,29.58,29.40,29.35,29.29$, 26.08, 22.69, 14.13. MS (MALDI-TOF): calcd for $\mathrm{C}_{88} \mathrm{H}_{120} \mathrm{Br}_{2} \mathrm{O}_{4} \mathrm{~S}_{2}$ $[\mathrm{M}]^{+}, 1464.6974$; found: 1464.7075 .

4.4.4. Synthesis of PIDT3T. To a $25 \mathrm{ml}$ flask, 2,7-dibromo4,9-dihydro-4,4,9,9-(p-dodeoxyphenyl)-s-indaceno[1,2-b:5,6--b']dithiophene $(254 \mathrm{mg}, 0.2 \mathrm{mmol}), 2,5^{\prime \prime}$-bis(trimethylstannyl)$5,2^{\prime}, 5^{\prime}, 2^{\prime \prime}$-terthiophene (115 mg, $\left.0.2 \mathrm{mmol}\right), \mathrm{Pd}_{2}(\mathrm{dba})_{3}(5.5 \mathrm{mg}$, $0.006 \mathrm{mmol})$, and tri $(o$-tolyl $)$ phosphine $(11 \mathrm{mg}, 0.036 \mathrm{mmol})$ were added under nitrogen protection. After the addition of toluene $(5 \mathrm{ml})$, the mixture was heated to $110{ }^{\circ} \mathrm{C}$ and maintained at the same temperature for $24 \mathrm{~h}$. After cooling to room temperature, the mixture was poured into methanol. The precipitate was collected and purified by column chromatography over silica using chloroform as the eluant. After removing the solvent, the resulting red solid was dissolved into a small amount of chloroform and then poured methanol again. The product was collected and dried overnight under vacuum with the yield $81 \%$ for PIDT3T as a red solid. ${ }^{1} \mathrm{H}$ NMR $(600 \mathrm{MHz}$, $\left.\mathrm{CDCl}_{3}\right): \delta(\mathrm{ppm}) 7.34(\mathrm{~s}, 2 \mathrm{H}), 7.18-6.80(\mathrm{~m}, 24 \mathrm{H}), 3.91(\mathrm{br}, 8 \mathrm{H})$, 1.75 (br, 8H), 1.42 (br, 8H), 1.35-1.20 (m, 64H), $0.87(\mathrm{t}, J=7.0$ $\mathrm{Hz}, 12 \mathrm{H}$ ). GPC (THF at room temp.): $M_{\mathrm{n}}=61.7 \mathrm{~K}, M_{\mathrm{w}}=62.6 \mathrm{~K}$, $\mathrm{PDI}=1.01$

4.4.5. Synthesis of PIDTDTBT. To a $25 \mathrm{ml}$ flask, 2,7dibromo-4,9-dihydro-4,4,9,9-( $p$-dodeoxyphenyl)-s-indaceno[1,2b:5,6-b']dithiophene $\quad(254 \mathrm{mg}, \quad 0.2 \mathrm{mmol}), \quad 4,7-\mathrm{di}(2-$ trimethylstannylthiophen-5-yl)-2,1,3-benzothiadiazole (125 mg, $0.2 \mathrm{mmol}), \mathrm{Pd}_{2}(\mathrm{dba})_{3}(5.5 \mathrm{mg}, 0.006 \mathrm{mmol})$ and tri $(o$-tolyl $)$ phosphine $(11 \mathrm{mg}, 0.036 \mathrm{mmol})$ were added under nitrogen protection. The other procedures are just as PIDT3T. The product was obtained with the yield $63 \%$ for PIDTDTBT as a dark-blue solid. ${ }^{1} \mathrm{H}$ NMR $\left(600 \mathrm{MHz}, \mathrm{CDCl}_{3}\right): \delta(\mathrm{ppm})$ 8.01-7.84 (m, 4H), $7.38(\mathrm{br}, 2 \mathrm{H}), 7.23-6.81(\mathrm{~m}, 20 \mathrm{H}), 3.92(\mathrm{br}, 8 \mathrm{H}), 1.75(\mathrm{br}$, $8 \mathrm{H}), 1.43(\mathrm{br}, 8 \mathrm{H}), 1.37-1.20(\mathrm{~m}, 64 \mathrm{H}), 0.86(\mathrm{t}, J=7.0 \mathrm{~Hz}, 12 \mathrm{H})$. GPC (THF at room temp.): $M_{\mathrm{n}}=35.1 \mathrm{~K}, M_{\mathrm{w}}=44.3 \mathrm{~K}, \mathrm{PDI}=1.26$.

\section{Acknowledgements}

The authors are deeply grateful to the National Natural Science Foundation of China (Project no. 21274134, 21202181, 51303197 and 51173199), New Century Excellent Talents in University (NCET-11-0473), and Qingdao Municipal Science and Technology Program (13-1-4-200-jch) for financial support. 


\section{References}

1 C. J. Barbec, Sol. Energy Mater. Sol. Cells, 2004, 83, 273-292.

2 H. C. Chen, Y. H. Chen, C. C. Liu, Y. C. Chien, S. W. Chou and P. T. Chou, Chem. Mater., 2012, 24, 4766-4772.

3 M. Zhang, Y. Gu, X. Guo, F. Liu, S. Zhang, L. Huo, T. P. Russell and J. Hou, Adv. Mater., 2013, 25, 4944-4949.

4 M. Zhang, X. Guo, W. Ma, S. Zhang, L. Huo, H. Ade and J. Hou, Adv. Mater., 2014, 26, 2089-2095.

5 J. Yuan, Z. Zhai, H. Dong, J. Li, Z. Jiang, Y. Li and W. Ma, Adv. Funct. Mater., 2013, 23, 885-892.

6 M. C. Scharber and N. S. Sariciftci, Prog. Polym. Sci., 2013, 38, 1929-1940.

7 Q. Liu, X. C. Bao, S. G. Wen, Z. K. Du, L. L. Han, D. Q. Zhu, Y. H. Chen, M. L. Sun and R. Q. Yang, Polym. Chem., 2014, 5, 2076-2082.

8 J. You, L. Dou, K. Yoshimura, T. Kato, K. Ohya, T. Moriarty, K. Emery, C. C. Chen, J. Gao, G. Li and Y. Yang, Nat. Commun., 2013, 4, 1446.

9 G. Yu, J. Gao, J. C. Hummelen, F. Wudl and A. J. Heeger, Science, 1995, 270, 1789-1791.

10 C. Li, M. Liu, N. G. Pschirer, M. Baumgarten and K. Müllen, Chem. Rev., 2010, 110, 6817-6855.

11 Y. J. Cheng, S. H. Yang and C. S. Hsu, Chem. Rev., 2009, 109, 5868-5923.

12 Y. Li and Y. Zou, Adv. Mater., 2008, 20, 2952-2958.

13 E. Bundgaard and F. Krebs, Sol. Energy Mater. Sol. Cells, 2007, 91, 954-985.

14 J. Roncali, Chem. Rev., 1997, 97, 173-206.

15 Y. Chen, C. Yu, Y. Fan, L. Hung, C. Chen and C. Ting, Chem. Commun., 2010, 46, 6503-6505.

16 Y. Zhang, J. Zou, H. L. Yip, K. S. Chen, D. F. Zeigler, Y. Sun and A. K. Y. Jen, Chem. Mater., 2011, 23, 2289-2291.

17 W. M. Zhang, J. Smith, S. E. Watkins, R. Gysel, M. McGehee, A. Salleo, J. Kirkpatrick, S. Ashraf, T. Anthopoulos, M. Heeney and I. McCulloch, J. Am. Chem. Soc., 2010, 132, 11437-11439.

18 S. Ando, J. Nishida, H. Tada, Y. Inoue, S. Tokito and Y. Yamashita, J. Am. Chem. Soc., 2005, 127, 5336-5337.

19 M. Zhang, X. Guo, X. Wang, H. Wang and Y. Li, Chem. Mater., 2011, 23, 4264-4270.

20 Y. C. Chen, C. Y. Yu, Y. L. Fan, L. I. Hung, C. P. Chen and C. Ting, Chem. Commun., 2010, 46, 6503-6505.

21 C. P. Chen, Y. C. Chen and C. Y. Yu, Polym. Chem., 2013, 4, 1161-1166.

22 R. S. Ashraf, B. C. Schroeder, H. A. Bronstein, Z. Huang, S. Thomas, R. J. Kline, C. J. Brabec, P. Rannou, T. D. Anthopoulos, J. R. Durrant and I. McCulloch, Adv. Mater., 2013, 25, 2029-2034.

23 S. H. Chan, C. P. Chen, T. C. Chao, C. Ting, C. S. Lin and B. T. Ko, Macromolecules, 2008, 41, 5519-5526.

24 K. S. Chen, Y. Zhang, H. L. Yip, Y. Sun, J. A. Davies, C. Ting, C. P. Chen and A. K. Y. Jen, Org. Electron., 2011, 12, 794-801.
25 Y. X. Xu, C. C. Chueh, H. L. Yip, F. Z. Ding, Y. X. Li, C. Z. Li, X. Li, W. C. Chen and A. K. Jen, Adv. Mater., 2012, 24, 63566541.

26 Y. Zhang, J. Zou, H.-L. Yip, K.-S. Chen, J. A. Davies, Y. Sun and A. K. Y. Jen, Macromolecules., 2011, 44, 4752-4758.

27 Y. Sun, S. C. Chien, H. L. Yip, Y. Zhang, K. S. Chen, D. F. Zeigler, F. C. Chen, B. Lin and A. K. Y. Jen, J. Mater. Chem., 2011, 21, 13247-13255.

28 Y. Zhang, S. C. Chien, K. S. Chen, H. L. Yip, Y. Sun, J. A. Davies, F. C. Chen and A. K. Y. Jen, Chem. Commun., 2011, 47, 11026-11028.

29 Y. X. Xu, C. C. Chueh, H. L. Yip, F. Z. Ding, Y. X. Li, C. Z. Li, X. Li, W. C. Chen and A. K. Jen, Adv. Mater., 2012, 24, 63566361.

30 W. Zhang, J. Smith, S. E. Watkins, R. Gysel, M. McGehee, A. Salleo, J. Kirkpatrick, S. Ashraf, T. Anthopoulos, M. Heeney and I. McCulloch, J. Am. Chem. Soc., 2010, 132, 11437-11439.

31 L. Huo, X. Guo, S. Zhang, Y. Li and J. H. Hou, Macromolecules, 2011, 44, 4035-4037.

32 Z. He, C. Zhong, X. Huang, W. Y. Wong, H. Wu, L. Chen, S. Su and Y. Cao, Adv. Mater., 2011, 23, 4636-4643.

33 J. Mei and Z. Bao, Chem. Mater., 2014, 26, 604-615.

34 K. T. Wong, T. C. Chao, L. C. Chi, Y. Y. Chu, A. Balaiah, S. F. Chiu, Y. H. Liu and Y. Wang, Org. Lett., 2006, 8, 50335036.

35 Z. N. Bao, W. K. Chan and L. P. Yu, J. Am. Chem. Soc., 1995, 117, 12426-12435.

36 C. Kitamura, S. Tanaka and Y. Yamashita, Chem. Mater., 1996, 8, 570-578.

37 J. P. Beny, S. N. Dhawan, J. kagan and S. Sundlass, J. Org. Chem., 1982, 47, 2201-2204.

38 C. Duan, K. S. Chen, F. Huang, H. L. Yip, S. Liu, J. Zhang, A. K. Y. Jen and Y. Cao, Chem. Mater., 2010, 22, 6444-6452.

39 Q. Peng, X. Liu, D. Su, G. Fu, J. Xu and L. Dai, Adv. Mater., 2011, 23, 4554-4558.

40 Y. F. Li, Y. Cao, J. Gao, D. L. Wang, G. Yu and A. J. Heeger, Synth. Met., 1999, 99, 243-248.

41 M. L. Sun, L. Wang, Y. J. Xia, B. Du, R. S. Liu and Y. Cao, Acta Polym. Sin., 2007, 10, 952-958.

42 M. L. Sun, L. Wang, X. H. Zhu, B. Du, R. S. Liu, W. Yang and Y. Cao, Sol. Energy Mater. Sol. Cells, 2007, 91, 1681-1687.

43 M. L. Sun, L. Wang, B. Du, R. S. Liu and Y. Cao, Synth. Met., 2008, 158, 125-129.

44 S. C. Price, A. C. Stuart and W. You, Macromolecules, 2010, 43, 4609-4612.

45 L. S. Liebeakind and J. Y. Wang, J. Org. Chem., 1993, 58, 3550-3556.

46 A. Kraft, A. C. Grimsdale and A. B. Holmes, Angew. Chem., Int. Ed., 1998, 37, 402-428.

47 X. M. Liu, T. T. Lin, J. C. Huang, X. T. Hao, K. S. Ong and C. B. He, Macromolecules, 2005, 38, 4157-4168. 